\title{
perifèria
}

Número 13, diciembre 2010

www.periferia.name

\section{La mirada antropológica a los objetos}

\author{
Dolors Agulló Hernández - Universidad Autónoma de Barcelona ${ }^{1}$
}

\begin{abstract}
Resumen
Los textos que presentaremos son fruto del trabajo colaborativo entre doctorandos/as que participamos en el seminario "Temas de antropología religiosa de España", impartido por William A. Christian. Este seminario, incluido en el programa de Master en Antropología social y cultural de la Universidad Autónoma de Barcelona, pretende proporcionar habilidades y enfoques útiles para el estudio de la religiosidad en el presente y en el pasado, pero en un contexto más amplio y desde una perspectiva un tanto particular, ya que pretende proporcionar una mirada antropológica a los objetos.

Todo lo que trabajamos en el seminario estaba destinado a proporcionar un aprendizaje práctico. Los participantes aprendimos haciendo y también compartiendo nuestros hallazgos en el transcurso de los ejercicios. Incluso contamos con la participación de estudiantes que habían participado en seminarios anteriores y personas que habían tenido una relación especial con determinados objetos. Y en el proceso de ese hacer y compartir, nos encontramos con notables contrastes que en ocasiones nos introducía en materia de religión y en todo un mundo de simbolismo, significado y significantes, pero en cualquier caso nos proporcionó una experiencia antropológica de gran magnitud.
\end{abstract}

Palabras claves: Práctica de investigación, experiencia antropológica, objetos, religión, simbolismo, cultura material.

\begin{abstract}
These case studies are the result of collaborative work between doctoral students who participated in the seminar "Issues of religious anthropology of Spain", by William A. Christian. This seminar, included in the Master program in Social and Cultural Anthropology at the Autonomous University of Barcelona, aims to provide useful skills and approaches to the religion study in the present and the past, but in a broader context and from a somewhat particular perspective, as it involves an anthropological look at objects.
\end{abstract}

The seminar was designed to provide practical learning. Participants learned by doing and sharing findings in the course of exercises. The classes include students from previous workshops and persons with special relationships with certain objects. And in the process of doing and sharing, we found contrasts that at times

\footnotetext{
${ }^{1}$ Enviar correspondencia a: Dolors Agulló dolorsaplec@gmail.com
} 


\section{perifèria}

Número 13, diciembre 2010

www.periferia.name

took us into religion and a world of symbolism, meaning and significance, but in any case, provided a profound anthropological experience.

Key words: Research exercise, anthropological experience, objects, religion, symbolism, material culture.

El objetivo del seminario "Temas de antropología religiosa " es proporcionar a los participantes un nuevo enfoque, una nueva forma de observar desde otra perspectiva, ya que se nos invitaba a realizar una observación participante en torno a los "objetos".

Lo cierto es que a la mayoría de los alumnos y alumnas nos fascinó participar en dicho seminario, ya que aprendimos a observar con otros ojos el concepto, bien arraigado en Antropología, de mirar "al otro". Esta experiencia nos ayudó a dar un paso más en la tarea de desarrollar esa mirada antropológica sobre los temas religiosos.

Es imprescindible explicar con total sinceridad que en las primeras sesiones del seminario, se hacía muy difícil entender qué nos estaba intentando transmitir el profesor. Nos comentábamos unos a otros que el seminario no era lo que esperábamos de un experto en Antropología Religiosa en España. Tampoco sabíamos exactamente de qué forma la observación de objetos aparentemente inconexos nos podía ayudar a hacer antropología de algún modo; y si ya esto tenía su dificultad, comprender qué relación podían tener estas observaciones con el tema de antropología religiosa, todavía era más trabajoso.

Sin embargo, a medida que avanzábamos en la materia, todo cobraba sentido y finalmente para cada uno de nosotros quedaba claro que todo mundo religioso y simbólico, está construido alrededor de objetos con distintos valores y significados para los prosélitos. Asimismo discernimos que este paradigma no es exclusivo de lo religioso, ya que cualquier objeto, imagen o representación puede tener un fuerte simbolismo, capaz de establecer, perpetuar o destruir relaciones entre individuos y otros (vivos, muertos, deidades, espíritus, etc.).

En ocasiones pensamos que el único modo de hacer un trabajo etnográfico es 


\section{perifèria}

Número 13, diciembre 2010

www.periferia.name

planteando hipótesis o supuestos de partida, estableciendo variables o la aplicabilidad de lo que vamos a estudiar, cuando en realidad la etnografía se hace a partir de aquella relación que establecemos con las personas, relación a partir de la cual obtenemos conocimiento de cómo establecen estas sus respectivas relaciones. Claro que, enunciado de este modo, pareciera que la etnografía de proyecto está de más, evidentemente no es así. Pero lo que sí queremos expresar es que en el seminario, hemos aprendido que la etnografía se puede iniciar a partir de cada relación que establecemos cotidianamente, a partir de cada objeto que observamos, y que el campo de trabajo puede ser tan cercano como podamos imaginar.

Así pues, todo un nuevo panorama se abría ante nosotros. El seminario abrió un mundo de posibilidades de reflexión antropológica. Sabemos que no lo podemos llamar "antropología de los objetos", pero lo cierto es que tras la participación en el seminario, la mayoría de nosotros somos capaces de mirar los objetos, las cosas, las "no cosas", desde otra perspectiva.

Como bien hemos aprendido, podemos "entrevistar a los objetos"; y realmente responden, de manera que se puede hacer un verdadero trabajo de campo analizando un objeto. Es cierto que se precisa ejercitar en extremo la capacidad de observación, de interrogación e interpretación, pero... ¿qué es si no la antropología?. Por todo ello creemos que si el propósito de William A. Christian era enseñarnos antropología religiosa sin teoría, sino desde la más abrupta experimentación, sin duda lo consiguió.

El trabajo etnográfico que cada participante realizó para el seminario, nos llevó a poner de relieve que los objetos pueden llegar a tener un gran valor simbólico y aunque la sociedad de hoy niega o intenta huir de todo ritualismo religioso, el papel simbólico que juegan los objetos y las propiedades que les damos, consciente o inconscientemente, es muy poderoso. El trabajo fue toda una experiencia etnográfica, aunque discreta y basada en unas pocas entrevistas y a partir del intento de descubrir la relación entre personas a partir de un objeto.

Por tanto la propuesta fue esa mirada diferente, una mirada profunda a través del 


\section{perifèria}

Número 13, diciembre 2010

www.periferia.name

objeto, mirar hacia dentro, hacia fuera y hacia los lados, haciendo emerger con todo ello las relaciones que a partir de esas cosas, se establecen o se destruyen entre los individuos. Todo ello, consiguiendo además que el propio observador acabe involucrándose (participante) casi sin darse cuenta; se contagie, estableciéndose la contemplación maravillada por la propia implicación. Esta mirada tiene que acabar por enfrentarse e investigar la transmisión oral de las personas a las que les atañe en algún modo el objeto que se estudia. Estos objetos podían ser cualquier cosa moderna o antigua; de cualquier tipo, fotografías, monedas, anillos, programas de teatro, vestidos antiguos o genealogías, incluso "no objetos" (cosas inmateriales).

Cada cosa que observásemos podía llevarnos a desarrollar una antropología "de batalla", de cada día y esto es importante tenerlo en cuenta, ya que tenemos que ser realistas y conscientes de que al finalizar nuestra formación no todos podremos dedicarnos a hacer investigación etnográfica patrocinada; pero si nos gusta la antropología, todos podemos hacer etnografía "de batalla" y si lo hacemos con rigor antropológico, respeto y nos atrevemos a escribir aquello que descubrimos, estaremos haciendo nuestra aportación para la comprensión de "los otros".

\section{Cómo estos objetos conectan o desconectan a las personas con otras personas, con lo sagrado, o con el cosmos.}

Al hablar de este estudio de la antropología a partir de los objetos, surgen cuestiones como: ¿por qué ciertos objetos cobran relevancia en la vida de las personas y otros no? ¿Por qué los objetos (o ciertos objetos) pueden ser nexo de unión o desunión entre individuos, familias, colectividades, etc.? El intento de dar respuesta a estas cuestiones nos lleva irremediablemente a procurar establecer qué es lo que conecta o desconecta a los objetos con las personas, con lo sagrado, con los difuntos, etc.

Entendimos que fuera cual fuera el ideario respecto al objeto o tipo de objeto, el nexo de unión entre objeto e individuo es un sentimiento sea del tipo que sea. Puede ser desde esa devoción de un adolescente por su celular, siendo casi un 


\section{perifèria}

Número 13, diciembre 2010

www.periferia.name

objeto de idolatría; o un arcón entero de fotografías de seres queridos o fotografías expuestas en rincones entrañables de un hogar; así como pequeñas joyas sin apenas valor pero guardadas como un tesoro.

Evidentemente el valor dado a los objetos es otorgado por los sentimientos que perduran a través del tiempo (en ocasiones a través del espacio) y de algún modo esos sentimientos no son otra cosa que una proyección hacia las personas, lugares, anhelos, sueños, deseos, miedos, etc., que esos objetos proyectan.

Respecto a la capacidad simbólica de los objetos, se hace necesario decir que las personas dan el valor a los objetos o no objetos, normalmente sin consciencia ninguna de ello, por los vínculos afectivos que estos objetos traen a la memoria. Sentimientos rememorados ante el objeto, sentimientos que se establecieron a partir de relaciones estrechas, que se dieron o que se habrían deseado tener. Lo cierto es que los objetos no tienen más valor que aquel que nuestro ideario (ideas, reconocimiento de sentimientos, recuerdos) quiera darles.

Por tanto la vinculación que se establece con los objetos puede tomar diferentes formas, dependiendo de las emociones que estos objetos suscitan a las personas que los poseen; también este lazo depende de la edad de las personas, de la caducidad o transitoriedad de los objetos, incluso de la intangibilidad de los no objetos. Asimismo entendemos que esa vinculación puede venir dada por la necesidad del ser humano de buscar sentido a la vida, a las cosas que nos suceden o también puede deberse al deseo muy humano de mantener la memoria de aquello que hemos vivido, de las personas o hechos que nos han resultado significativos, del mismo modo que el temor a la muerte definitiva que es el olvido puede formar parte de esa sujeción a los objetos.

En esta exposición colaborativa hemos escogido tres trabajos del seminario "Temas de antropología religiosa de España" que muestran el enorme alcance y riqueza que puede proporcionar la mirada a los objetos. Como ya hemos visto, no necesariamente los objetos de estos tres casos están relacionados con temas de religión, pero sí nos muestran muy bien el simbolismo que se puede establecer alrededor de los objetos y como esta simbología marca las relaciones entre 


\section{perifèria}

Número 13, diciembre 2010

www.periferia.name

individuos.

Por un lado, Wilson Muñoz nos muestra el caso de "dos celulares" (teléfonos móviles), en el que vemos la relevancia de estos aparatos en el ideario de unas adolescentes y cómo a través de ellos se refrenda la propia identidad, al mismo tiempo que se conforman como un sello de integración social. Por otro lado, Maite Marín nos habla de unos "objetos en el exilio". Cada uno de estos objetos, con su propia historia, se han convertido en un transporte al pasado, a los recuerdos, una evocación a la vida dejada atrás. El tercero de los trabajos, que nos trae Cristina Cocco, hace referencia a unos no objetos, "las almas"; almas que pertenecían a personas condenadas en vida por transgresiones contra la moral popular, matizando las nuevas posibilidades en las relaciones sociales en el lugar en el que transcurre el relato.

Veamos todos y cada uno de estos objetos como residuos o almacenes de emociones, de memorias e incluso de anhelos, de los individuos y colectividades relacionadas con esos objetos. Todos tienen un extraordinario ideario detrás que sustenta la relevancia que se les da, pero además trascienden la creencia que les acompaña y acaban conectando con afección o desafección a las personas. 